\title{
Ethene-trans-1,2-bis(4-pyridinium) Dihydrogenphosphite and Dihydrogenphosphate Compounds Exhibiting Cooperative and Directed Hydrogen Bonds between Cations and Anions: $\mathrm{H}_{2} \mathrm{bpe}\left(\mathrm{H}_{2} \mathrm{PO}_{3}\right)_{2}$ and $\mathrm{H}_{2} \mathrm{bpe}\left(\mathrm{H}_{2} \mathrm{PO}_{4}\right)_{2} \cdot \mathrm{H}_{2} \mathrm{O}$
}

\author{
Veysel T. Yilmaz ${ }^{\mathrm{a}}$, Selcuk Demir ${ }^{\mathrm{a}}$, and William T. A. Harrison ${ }^{\mathrm{b}}$ \\ a Department of Chemistry, Faculty of Arts and Sciences, Ondokuz Mayis University, \\ 55139 Kurupelit, Samsun, Turkey \\ ${ }^{b}$ Department of Chemistry, University of Aberdeen, Meston Walk, Aberdeen AB24 3UE, \\ Scotland, UK \\ Reprint requests to Prof. Dr. V.T. Yilmaz. E-mail: vtyilmaz@omu.edu.tr
}

Z. Naturforsch. 61b, 1067 - 1071 (2006); received March 27, 2006

\begin{abstract}
$\mathrm{H}_{2}$ bpe $\left(\mathrm{H}_{2} \mathrm{PO}_{3}\right)_{2}(\mathbf{1})$ and $\mathrm{H}_{2}$ bpe $\left(\mathrm{H}_{2} \mathrm{PO}_{4}\right)_{2} \cdot \mathrm{H}_{2} \mathrm{O}(2)\left(\mathrm{H}_{2}\right.$ bpe = ethene-trans-1,2-bis(4-pyridinium), $\mathrm{H}_{2} \mathrm{PO}_{3}=$ dihydrogenphosphite, and $\mathrm{H}_{2} \mathrm{PO}_{4}=$ dihydrogenphosphate) have been prepared and structurally characterized. In compound $\mathbf{1}$, the dihydrogenphosphite anions form dimers, with a P ..P distance of 4.2073(7) $\AA$, by two $\mathrm{O}-\mathrm{H} \cdots \mathrm{H}$ hydrogen bonds, and the dimeric dihydrogenphosphite units interact with the $\mathrm{H}_{2}$ bpe cations by way of $\mathrm{N}-\mathrm{H} \cdots \mathrm{O}$ and $\mathrm{O}-\mathrm{H} \cdots \mathrm{O}$ hydrogen bonds, resulting in a one-dimensional chain. The chains are held together by $\mathrm{C}-\mathrm{H} \cdots \mathrm{O}$ interactions. In compound $\mathbf{2}$, the phosphate ions are connected by $\mathrm{O}-\mathrm{H} \cdots \mathrm{O}$ hydrogen bonds into an unusual $2 \mathrm{D}$ square gridtype framework with P...P separations ranging from 4.7533(7) to 4.9506(8) $\AA$. The $\mathrm{H}_{2}$ bpe cations crosslink the dihydrogen phosphate layers by $\mathrm{N}-\mathrm{H} \cdots$ O hydrogen bonds, forming a three-dimensional supramolecular network with channels. The water molecules in compound $\mathbf{2}$ occupy these channels and make $\mathrm{O}-\mathrm{H} \cdots \mathrm{O}$ bonds to adjacent phosphate $\mathrm{O}$ atoms and also $\mathrm{O}-\mathrm{H} \cdots \mathrm{O}$ bonds to the next water $\mathrm{O}$ atom in the channel.
\end{abstract}

Key words: Dihydrogenphosphites, Dihydrogenphosphates, Ethene-trans-1,2-bis(4-pyridinium) Cations, Hydrogen Bonds, Crystal Structure

\section{Introduction}

In the formation of organic-templated phosphates, protonated organic amines play an important role. For example, they act as structure-directing agents, usually occupying the available voids or channels, and stabilize the structure via hydrogen bonding and other intermolecular interactions $[1-4]$. Furthermore, the organic amine acts as a ligand to metal ions and it has been shown that the number of amino groups has significant effects on these materials and the use of diamines, triamines or tetramines seems to be more effective than that of monoamines [5-8]. Sometimes, organic ammonium phosphates are formed as intermediates or by-products in the synthesis of organictemplated metal phosphates [9-11]. They exhibit interesting crystal packing motifs strongly influenced by $\mathrm{N}-\mathrm{H} \cdots \mathrm{O}$ and $\mathrm{O}-\mathrm{H} \cdots \mathrm{O}$ hydrogen bonds $[12-16]$. In some cases, hydrogen bonding results in a threedimensional supramolecular array of phosphate ions and the organic ammonium cations are encapsulated in the channels of the framework $[17,18]$.

As a part of our work on the preparation and structural characterization of organic ammonium phosphates, in this paper, we report the characterization and structures of two ionic compounds of the ethene-trans-1,2-bis(4-pyridinium) dication $\left(\mathrm{H}_{2}\right.$ bpe $)$ with dihydrogenphosphite and dihydrogenphosphate anions, namely $\mathrm{H}_{2}$ bpe $\left(\mathrm{H}_{2} \mathrm{PO}_{3}\right)_{2}$ (1) and $\mathrm{H}_{2}$ bpe $\left(\mathrm{H}_{2}\right.$ $\left.\mathrm{PO}_{4}\right)_{2} \cdot \mathrm{H}_{2} \mathrm{O}(2)$.

\section{Results and Discussion \\ Description of the crystal structures}

The structure of $\mathbf{1}$ is built up from $\left[\mathrm{H}_{2} \mathrm{PO}_{3}\right]^{-}$dihydrogenphosphite anions and ethene-trans-1,2-bis(4pyridinium) cations. The latter species is generated from the asymmetric unit by inversion symmetry (Fig. 1). Selected geometrical data are presented in Table 1 . The $\left[\mathrm{H}_{2} \mathrm{PO}_{3}\right]^{-}$moiety adopts its usual pseudo- 
Table 1. Selected bond lengths and angles, and hydrogen bonding geometry of $\mathbf{1}^{\mathrm{a}}$.

\begin{tabular}{llll}
\hline \multicolumn{2}{l}{ Bond lengths $\left(\stackrel{\circ}{ }\right.$ ) and angles $\left({ }^{\circ}\right)$} & & \\
$\mathrm{P} 1-\mathrm{O} 1$ & $1.4976(13)$ & $\mathrm{O} 1-\mathrm{P} 1-\mathrm{O} 2$ & $116.45(8)$ \\
$\mathrm{P} 1-\mathrm{O} 2$ & $1.5026(13)$ & $\mathrm{O} 1-\mathrm{P} 1-\mathrm{O} 3$ & $111.14(7)$ \\
$\mathrm{P} 1-\mathrm{O} 3$ & $1.5725(14)$ & $\mathrm{O} 2-\mathrm{P} 1-\mathrm{O} 3$ & $108.10(7)$ \\
$\mathrm{P} 1-\mathrm{H} 1$ & 1.3200 & &
\end{tabular}

Hydrogen bonds

D-H $\cdots \mathrm{A} \quad \mathrm{D}-\mathrm{H}(\AA) \quad \mathrm{H} \cdots \mathrm{A}(\AA) \quad \mathrm{D} \cdots \mathrm{A}(\AA) \quad \mathrm{D}-\mathrm{H} \cdots \mathrm{A}\left({ }^{\circ}\right)$

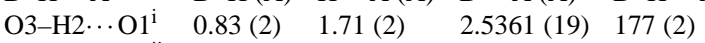

$\mathrm{N} 1-\mathrm{H} 3 \cdots \mathrm{O} 2^{\mathrm{ii}} \quad 0.92(2) \quad 1.66(2) \quad 2.5703(18) \quad 175(19)$

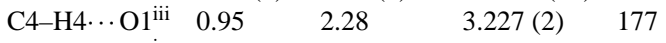

$\begin{array}{lllll}\mathrm{C} 5-\mathrm{H} 5 \cdots \mathrm{O}^{\text {iv }} & 0.95 & 2.42 & 3.319(2) & 158\end{array}$

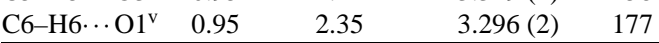

${ }^{\text {a }}$ Symmetry operations: ${ }^{\mathrm{i}} 1-x, 1-y,-z ;{ }^{\mathrm{ii}} x-1, y, z ;{ }^{\mathrm{iii}} x, 1 / 2-y$, $1 / 2+z$; ${ }^{\text {iv }}-x, y-1 / 2,1 / 2-z ;{ }^{\mathrm{v}} 1-x, 1 / 2+y, 1 / 2-z$.

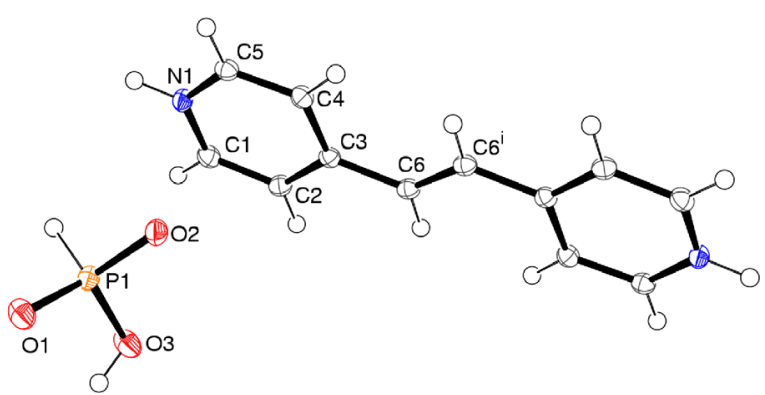

Fig. 1. A view of the asymmetric unit of $\mathbf{1}$ in the crystal, showing $50 \%$ displacement ellipsoids (arbitrary spheres for the $\mathrm{H}$ atoms). Symmetry code: $1-x, 1-y, 1-z$.

pyramidal geometry, and the $\mathrm{P}-\mathrm{O}$ bond lengths and angles are normal [mean $\mathrm{P}-\mathrm{O}=1.524(2) \AA]$. As expected, the protonated P1-O3 link is significantly longer than the unprotonated bonds.

As well as by electrostatic and van der Waals forces, the components in $\mathbf{1}$ interact by way of $\mathrm{N}-\mathrm{H} \cdots \mathrm{O}$ and $\mathrm{O}-\mathrm{H} \cdots \mathrm{O}$ hydrogen bonds to result in a crystal structure with strong one-dimensional character. The anions are self assembled into dimers $\left[\mathrm{P} 1 \cdots \mathrm{P} 1^{\mathrm{i}}=\right.$

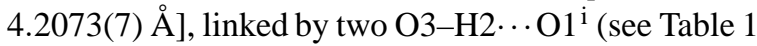
for symmetry codes) hydrogen bonds (Fig. 2). Then, the cations form $\mathrm{N}-\mathrm{H} \cdots \mathrm{O}$ bonds to result in a chain of alternating $\left(\left[\mathrm{H}_{2} \mathrm{PO}_{3}\right]^{-}\right)_{2}$ dimers and $\left[\mathrm{C}_{12} \mathrm{H}_{14} \mathrm{~N}_{2}\right]^{2+}$ cations that propagates in [201]. The unit-cell packing diagram in Fig. 2 shows that the chain orientations alternate between [201] and [201] with respect to the $b$ direction resulting in a pseudo layered structure. Along with the conventional hydrogen bonds, there are also some very short, nearly linear $\mathrm{C}-\mathrm{H} \cdots \mathrm{O}$ interactions (Table 1), which may provide some additional crosslinking in [010] between the pseudolayers. Any $\pi \cdots \pi$ stacking interactions in $\mathbf{1}$ must be
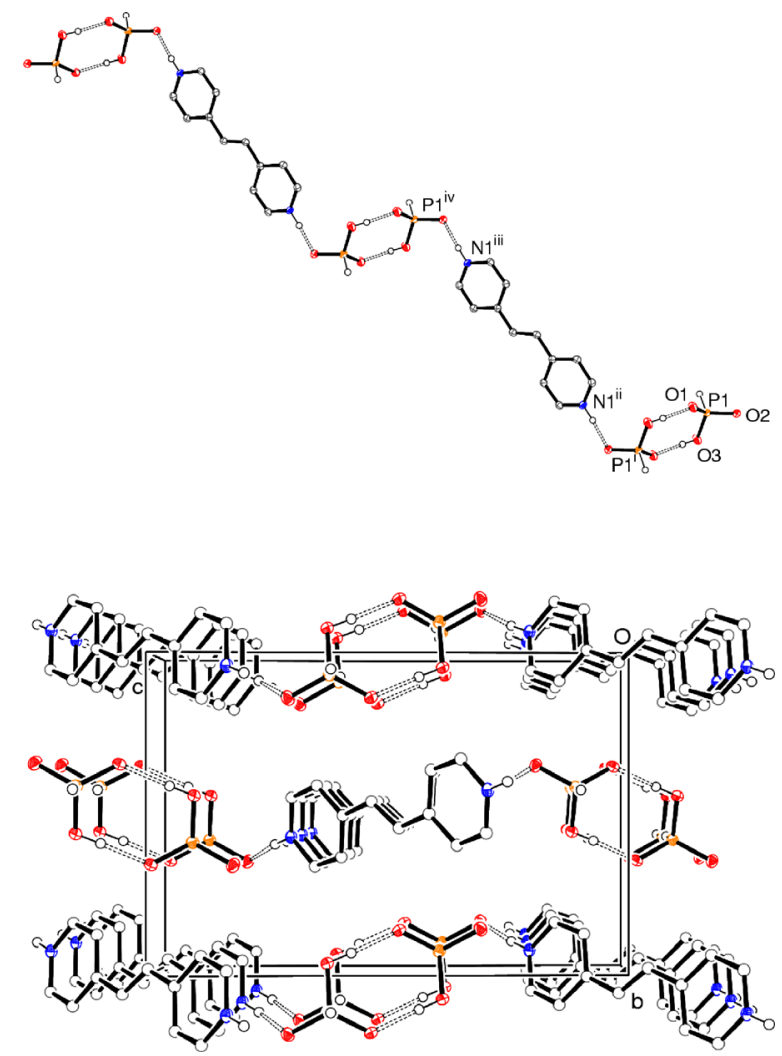

Fig. 2. Top: Interaction of the cations and anions via $\mathrm{N}-\mathrm{H} \cdots \mathrm{O}$ and $\mathrm{O}-\mathrm{H} \cdots \mathrm{O}$ hydrogen bonds, generating a onedimensional chain of $\mathbf{1}$. Symmetry codes (i) $=1-x, 1-y$, $-z$, (ii) $=-x, 1-y,-z$, (iii) $=x-1, y, z-1$ and (iv) $=$ $x-2, y, z-1$. Bottom: Packing diagram of 1 viewed along the $a$ axis. All $\mathrm{C}-\mathrm{H}$ hydrogen atoms have been omitted for clarity. Hydrogen bonds are indicated by dashed lines.

very weak, with a minimum ring-centroid separation of $4.67 \AA$.

The structure of $\mathbf{2}$ contains hydrogenphosphate anions, ethene-trans-1,2-bis(4-pyridinium) cations and water molecules. As with $\mathbf{1}$, the complete dication is generated by inversion symmetry (Fig. 3). Table 2 gives selected geometrical data. The $\left[\mathrm{H}_{2} \mathrm{PO}_{4}\right]^{-}$ group is normal, with the two $\mathrm{P}-\mathrm{OH}$ vertices showing the expected lengthening relative to the $\mathrm{P}-\mathrm{O}$ bonds which have formal partial double bond character [mean $\mathrm{P}-\mathrm{O}=1.538(2) \AA]$.

Again, hydrogen bonds appear to play a key role in establishing the crystal packing in $\mathbf{2}$. Both $\mathrm{P}-\mathrm{OH}$ vertices participate in $\mathrm{H}$ bonds to nearby anions to result (Fig. 4) in an unprecedented square network of phosphate ions. The graph theory notation [19] for this configuration is an $R_{4}^{4}(16)$ loop, and the nodal $\mathrm{P}$ atom 
Table 2. Selected bond lengths and angles, and hydrogen bonding geometry of $2^{\mathrm{a}}$.

\begin{tabular}{lcll}
\hline Bond lengths $(\dot{A})$ and angles $\left({ }^{\circ}\right)$ & & \\
P1-O1 & $1.4963(14)$ & O1-P1-O2 & $116.64(8)$ \\
P1-O2 & $1.5168(14)$ & O1-P1-O3 & $112.10(9)$ \\
P1-O3 & $1.5660(15)$ & O2-P1-O3 & $105.25(8)$ \\
P1-O4 & $1.5707(16)$ & O1-P1-O4 & $106.02(8)$ \\
& & O2-P1-O4 & $109.76(8)$ \\
& & O3-P1-O4 & $106.71(9)$
\end{tabular}

Hydrogen bonds

\begin{tabular}{|c|c|c|c|c|}
\hline $\mathrm{D}-\mathrm{H} \cdots \mathrm{A}$ & D-H $(\AA)$ & $\mathrm{H} \cdots \mathrm{A}(\AA)$ & $\mathrm{D} \cdots \mathrm{A}(\AA)$ & $\mathrm{D}-\mathrm{H} \cdots \mathrm{A}\left({ }^{\circ}\right)$ \\
\hline $\mathrm{O} 5-\mathrm{H} 4 \cdots \mathrm{O} 1$ & 0.94 & 1.98 & $2.894(2)$ & 164 \\
\hline $\mathrm{O} 3-\mathrm{H} 1 \cdots \mathrm{O} 2^{\mathrm{i}}$ & $0.82(3)$ & $1.76(3)$ & $2.576(2)$ & $176(3)$ \\
\hline $\mathrm{O} 4-\mathrm{H} 2 \cdots \mathrm{O} 1^{\mathrm{ii}}$ & $0.86(3)$ & $1.75(3)$ & $2.586(2)$ & $164(3)$ \\
\hline $\mathrm{O} 5-\mathrm{H} 5 \cdots \mathrm{O} 5^{\mathrm{iii}}$ & 0.97 & 1.89 & $2.862(4)$ & 173 \\
\hline $\mathrm{O} 5-\mathrm{H} 6 \cdots \mathrm{O}^{\mathrm{iv}}$ & 1.06 & 1.71 & $2.774(3)$ & 175 \\
\hline $\mathrm{N} 1-\mathrm{H} 3 \cdots \mathrm{O} 2^{\mathrm{v}}$ & $0.93(2)$ & $1.72(3)$ & $2.639(2)$ & $173(2)$ \\
\hline $\mathrm{C} 1-\mathrm{H} 1 \mathrm{a} \cdots \mathrm{O} 4$ & 0.95 & 2.48 & $3.273(2)$ & 141 \\
\hline $\mathrm{C} 5-\mathrm{H} 5 \mathrm{a} \cdots \mathrm{O} 1^{\mathrm{vi}}$ & 0.95 & 2.38 & 3.254 (2) & 152 \\
\hline
\end{tabular}

${ }^{a}$ Symmetry operations: ${ }^{\mathrm{i}} 1 / 2-x, 1 / 2+y, 3 / 2-z$; ${ }^{\mathrm{ii}} x,-y, 1 / 2+z$; ${ }^{\mathrm{iii}}-x, y, 2-z$; ${ }^{\mathrm{iv}}-x,-y, 1-z{ }^{\mathrm{v}} 1 / 2-x, 1 / 2-y, 2-z$; ${ }^{\mathrm{v}} x, 1-y$, $1 / 2+z$.

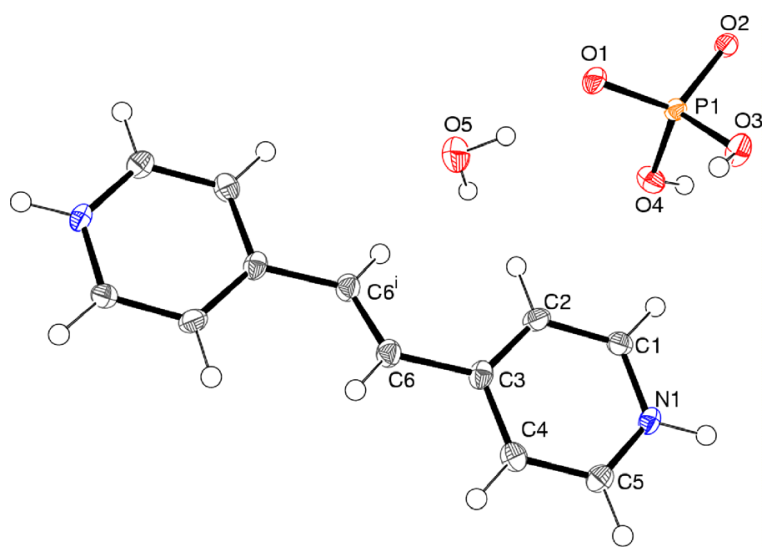

Fig. 3. A view of the asymmetric unit of 2 in the crystal with $50 \%$ displacement ellipsoids (arbitrary spheres for the $\mathrm{H}$ atoms). Symmetry codes (i) $=x, 1-y,-z$.

separations are $\mathrm{P} 1 \cdots \mathrm{P} 1^{\mathrm{i}}=4.7533(7)$ and $\mathrm{P} 1 \cdots \mathrm{P} 1^{\mathrm{ii}}=$ 4.9506 (8) $\AA$ ( $\mathrm{i}=x,-y, 1 / 2-z, \mathrm{ii}=1 / 2-x, y-1 / 2$, $3 / 2-z)$. The organic dication forms an $\mathrm{N}-\mathrm{H} \cdots \mathrm{O}$ hydrogen bond from each of its $\mathrm{N}$ atoms to crosslink the (100) dihydrogenphosphate sheets in the $a$ direction (Fig. 4). This connectivity of the $\left[\mathrm{H}_{2} \mathrm{PO}_{4}\right]^{-}$and $\left[\mathrm{C}_{12} \mathrm{H}_{14} \mathrm{~N}_{2}\right]^{2+}$ moieties results in a three-dimensional supramolecular scaffold that encloses channels propagating in [001]. These channels are occupied by the water molecules, which make $\mathrm{O}-\mathrm{H} \cdots \mathrm{O}$ bonds (via $\mathrm{H} 4$ ) to adjacent phosphate $\mathrm{O}$ atoms and also $\mathrm{O}-\mathrm{H} \cdots \mathrm{O}$ bonds (via the disordered $\mathrm{H} 5$ and $\mathrm{H} 6$ ) to the next water $\mathrm{O}$ atom in the channel. Locally each [001] column of water molecules has ordered $\mathrm{H}$ bonds as
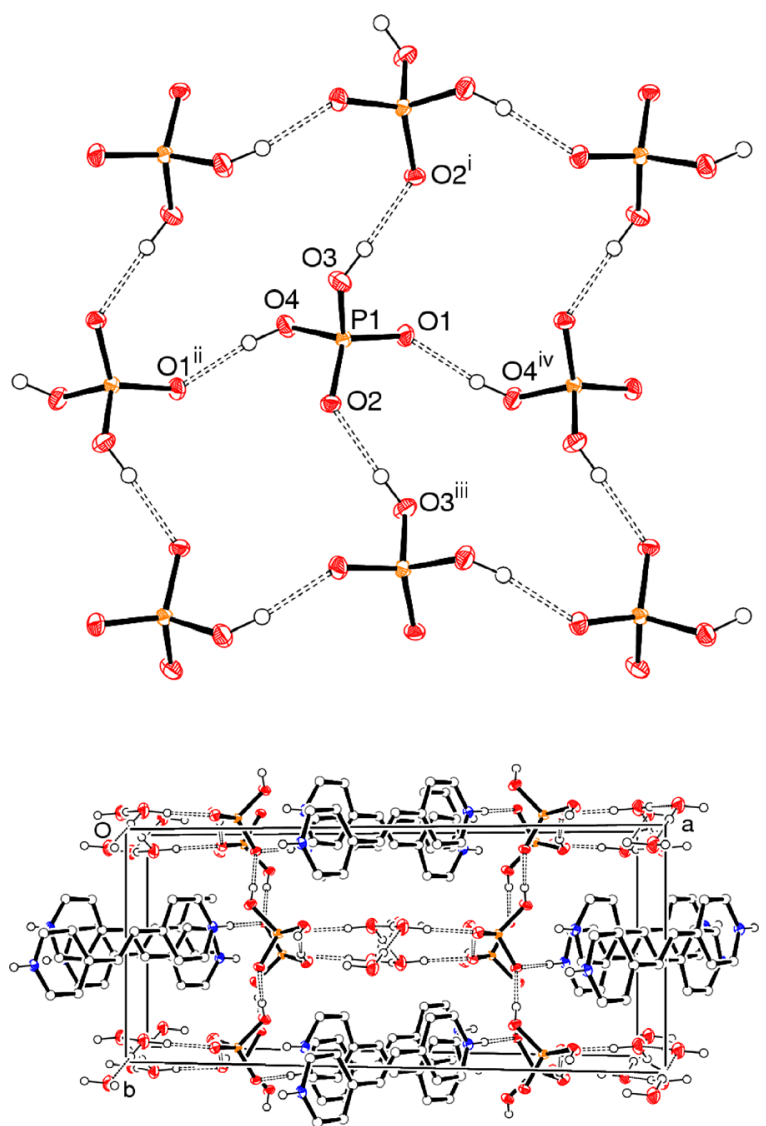

Fig. 4. Top: The two-dimensional phosphate framework of $\mathbf{2}$ formed by $\mathrm{O}-\mathrm{H} \cdots \mathrm{O}$ hydrogen bonds. Symmetry codes $(\mathrm{i})=$ $1 / 2-x, 1 / 2+y, 3 / 2-z$, (ii) $=x,-y, z+1 / 2$, (iii) $=1 / 2-x$, $y-1 / 2,3 / 2-z$ and (iv) $=x,-y, z-1 / 2$. Bottom: Packing diagram of 2 , showing hydrogen bonds. All $\mathrm{C}-\mathrm{H}$ hydrogen atoms have been omitted for clarity. Hydrogen bonds are indicated by dashed lines.

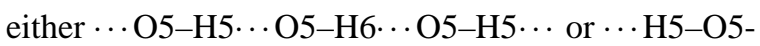
$\cdots \mathrm{H} 6-\mathrm{O} 5 \cdots \mathrm{H} 5-\mathrm{O} 5 \cdots$, but, as modelled here, there is no coherence between channels. Attempts to refine an ordered distribution of $\mathrm{H}$ bonds in lower symmetries were not successful. As in $\mathbf{1}$, some short $\mathrm{C}-\mathrm{H} \cdots \mathrm{O}$ contacts are present in $\mathbf{2}$ (Table 2), although their role, perhaps helping to anchor the dications to the (100) phosphate sheets, is not so clear-cut as in $\mathbf{1}$.

\section{IR spectra}

The IR spectra of compounds $\mathbf{1}$ and $\mathbf{2}$ are almost identical. The $v(\mathrm{O}-\mathrm{H})$ and $v(\mathrm{~N}-\mathrm{H})$ vibrations are expected to appear above $3000 \mathrm{~cm}^{-1}$, but they are observed as a strong single band centered at $3055 \mathrm{~cm}^{-1}$ for 1 and at $3030 \mathrm{~cm}^{-1}$ for $\mathbf{2}$, due to overlapping. The 


\begin{tabular}{|c|c|c|}
\hline & $\mathbf{1}$ & 2 \\
\hline Empirical formula & $\mathrm{C}_{12} \mathrm{H}_{16} \mathrm{~N}_{2} \mathrm{O}_{6} \mathrm{P}_{2}$ & $\mathrm{C}_{12} \mathrm{H}_{20} \mathrm{~N}_{2} \mathrm{O}_{10} \mathrm{P}_{2}$ \\
\hline$M_{\mathrm{r}}$ & 346.20 & 414.24 \\
\hline Crystal system & monoclinic & monoclinic \\
\hline Space group & $P 2_{1} / c$ & $C 2 / c$ \\
\hline$a[\AA]$ & $4.655(1)$ & $20.640(1)$ \\
\hline$b[\AA]$ & $10.331(1)$ & $9.033(1)$ \\
\hline$c[\AA]$ & $15.435(1)$ & $9.320(1)$ \\
\hline$\beta\left[^{\circ}\right]$ & $91.393(3)$ & $102.269(3)$ \\
\hline$V\left[\AA^{3}\right]$ & $741.98(4)$ & $1698.00(14)$ \\
\hline$Z$ & 2 & 4 \\
\hline$D_{\mathrm{c}}\left[\mathrm{g} / \mathrm{cm}^{3}\right]$ & 1.550 & 1.620 \\
\hline$\mu\left[\mathrm{mm}^{-1}\right]$ & 0.324 & 0.314 \\
\hline$F(000)$ & 360 & 861 \\
\hline Crystal size $\left[\mathrm{mm}^{3}\right]$ & $0.34 \times 0.07 \times 0.05$ & $0.40 \times 0.12 \times 0.02$ \\
\hline$\theta$ Range $\left[{ }^{\circ}\right]$ & $3.94-27.54$ & $3.19-27.53$ \\
\hline Index range $(h, k, l)$ & $-6 / 5,-13 / 13,-19 / 20$ & $-26 / 24,-11 / 11,-12 / 11$ \\
\hline Reflections collected & 9203 & 10244 \\
\hline Independent reflections $\left(R_{\text {int }}\right)$ & $1691(0.0416)$ & $1952(0.0453)$ \\
\hline Absorption correction & multi-scan & multi-scan \\
\hline Min. and max. transmission & 0.898 and 0.984 & 0.885 and 0.995 \\
\hline Data / parameters & $1691 / 107$ & $1952 / 128$ \\
\hline Goodness-of-fit on $F^{2}$ & 1.094 & 1.098 \\
\hline$R$ Indices $[I>2 \sigma(I)]$ & 0.0349 & 0.0404 \\
\hline$w R 2$ (all data) & 0.0809 & 0.0998 \\
\hline Largest diff. peak and hole $\left[\mathrm{e} . \AA^{-3}\right]$ & 0.32 and -0.41 & 0.33 and -0.49 \\
\hline
\end{tabular}

Table 3. Crystallographic data for $\mathbf{1}$ and 2 .

$C 2 /$

$320(1)$

$02.269(3)$

(14)

861

$-26 / 24,-11 / 11,-12 / 11$

10244

0.885 and 0.995

1952 / 128

0.33 and -0.49 sharp and strong band at $2336 \mathrm{~cm}^{-1}$ is assigned to the $\mathrm{P}-\mathrm{H}$ stretching vibration of the phosphite group of 1 , and the medium bands at 1651 and $1523 \mathrm{~cm}^{-1}$ are attributed to the ring stretching vibrations of the $\mathrm{H}_{2}$ bpe dication in both $\mathbf{1}$ and $\mathbf{2}$. Three distinct and strong bands at 1191, 1089 and $911 \mathrm{~cm}^{-1}$ correspond to the $\mathrm{P}-\mathrm{O}$ stretching vibrations of the phosphite anions of $\mathbf{1}$, whereas the strong bands at 1217, 1089 and $962 \mathrm{~cm}^{-1}$ characterize the $\mathrm{P}-\mathrm{O}$ stretching vibrations of the phosphate anions of $\mathbf{2}$.

\section{Experimental Section}

Materials and measurements

All reagents were commercially available and used without further purification. Elemental analyses $(\mathrm{C}, \mathrm{H}$, and $\mathrm{N})$ were carried out on an Elementar Vario EL elemental analyzer. The FT-IR spectra were recorded from $\mathrm{KBr}$ pellets in the range $4000-400 \mathrm{~cm}^{-1}$ by using a JASCO FT/IR-430 spectrophotometer.

\section{Synthesis of $\mathrm{H}_{2}$ bpe $\left(\mathrm{H}_{2} \mathrm{PO}_{3}\right)_{2}(\mathbf{1})$}

$5 \mathrm{ml}$ of an aqueous solution of $\mathrm{H}_{3} \mathrm{PO}_{3}(0.16 \mathrm{~g}, 2 \mathrm{mmol})$ was added dropwise to an aqueous mixture $(10 \mathrm{ml})$ of 1,2di(4-pyridyl)ethene (0.182 g, $1 \mathrm{mmol}$ ) and stirred for $20 \mathrm{~min}$ at $50{ }^{\circ} \mathrm{C}$. The resulting solution was then left to crystallize at r.t. Colorless crystals of $\mathbf{1}$ were collected, washed with a small amount of water, and dried in air. Yield 50\%. $\mathrm{C}_{12} \mathrm{H}_{16} \mathrm{~N}_{2} \mathrm{O}_{6} \mathrm{P}_{2}$ (346.20): calcd. C 41.63, $\mathrm{H} 4.66, \mathrm{~N}$ 8.09; found $\mathrm{C} 41.79$, H 4.76, N 7.87 .

\section{Synthesis of $\mathrm{H}_{2}$ bpe $\left(\mathrm{H}_{2} \mathrm{PO}_{4}\right)_{2} \cdot \mathrm{H}_{2} \mathrm{O}(\mathbf{2})$}

The preparation method for $\mathbf{2}$ was the same as described for 1 with $\mathrm{H}_{3} \mathrm{PO}_{4}$ replacing $\mathrm{H}_{3} \mathrm{PO}_{3}$. Yield $58 \%$. $\mathrm{C}_{12} \mathrm{H}_{20} \mathrm{~N}_{2} \mathrm{O}_{10} \mathrm{P}_{2}$ (414.24): calcd. C 34.79, H 4.87, N 6.76; found C 34.92, H 4.68, N 6.90.

\section{$X$-ray crystallography}

The data collections were performed at $120 \mathrm{~K}$ for both compounds on a Nonius Kappa-CCD diffractometer with graphite monochromated Mo- $K_{\alpha}$ radiation $(\lambda=$ $0.71073 \AA$ ). The structures were solved by Direct Methods using SHELXS-97 [20] and refined by a full-matrix least-squares procedure using the program SHELXL-97 [20]. All non-hydrogen atoms were easily found on the difference Fourier map and refined anisotropically. For both compounds, the $\mathrm{P}-\mathrm{OH}$ and $\mathrm{N}-\mathrm{H}$ hydrogen atoms were located in difference maps and their positions were freely refined. The C-bound $\mathrm{H}$ atoms were placed in idealized locations $(\mathrm{C}-\mathrm{H}=0.95 \AA)$ and refined as riding atoms. The water $\mathrm{H}$ atoms for $\mathbf{2}$ were located in difference maps and refined as riding in their as-found relative positions. The constraint $\mathrm{U}_{\text {iso }}(\mathrm{H})=1.2 \mathrm{U}_{\text {eq }}$ (carrier) was applied in all cases. The details of data collection, refinement and crystallographic data are summarized in Table 3. 
Crystallographic data have been deposited with the Cambridge Crystallographic Data Centre as supplementary publication no, CCDC-299941 (1) and CCDC-299942 (2). Copies of the data can be obtained on application to CCDC, 12 Union Road, Cambridge CB2 1EZ, UK [Fax: (internat.) +44-1223/336-033; E-mail: deposit@ccdc.cam.ac.uk].

\section{Acknowledgements}

We thank Ondokuz Mayis University for financial support and the EPSRC National Crystallography Service (University of Southampton, UK) for the data collection.
[1] A. Choudhury, S. Natarajan, C. N. R. Rao, Inorg. Chem. 39, 4295 (2000).

[2] W. T. A. Harrison, J. A. Rodgers, M. L. F. Phillips, T. M. Nenoff, Solid State Sci. 4, 969 (2002).

[3] V. T. Yilmaz, S. Demir, C. Kazak, W. T. A. Harrison, Solid State Sci. 7, 1247 (2005).

[4] T. Dorn, C. Janiak, K. Abu-Shandi, Cryst. Eng. Comm. 7, 633 (2005).

[5] W. T. A. Harrison, M. L.F. Phillips, Chem. Commun. 2771 (1996).

[6] W. T. A. Harrison, M. L.F. Phillips, Chem. Mater. 9, 1836 (1997).

[7] S. Neeraj, S. Natarajan, C. N. R. Rao, Chem. Mater. 11, 1390 (1999).

[8] S. Neeraj, S. Natarajan, C. N. R. Rao, Chem. Commun. 3480 (1999).

[9] S. Oliver, A. J. Lough, G. A. Ozin, Inorg. Chem. 37, 5021 (1998).

[10] S. Neeraj, S. Natarajan, C. N. R. Rao, Angew. Chem. Int. Ed. 38, 3480 (1999).
[11] C. N. R. Rao, S. Natarajan, S. Neeraj, J. Solid State Chem. 152, 302 (2000).

[12] S. Demir, V. T. Yilmaz, O. Andac, W. T. A. Harrison, Acta Crystallogr. C58, o407 (2002).

[13] S. Demir, V. T. Yilmaz, W. T. A. Harrison, Acta Crystallogr. C59, o378 (2003).

[14] S. Demir, V. T. Yilmaz, W. T. A. Harrison, Acta Crystallogr. E59, o907 (2003).

[15] S. Demir, V. T. Yilmaz, W. T. A. Harrison, Acta Crystallogr. C61, o565 (2005).

[16] S. Demir, V. T. Yilmaz, W. T. A. Harrison, Acta Crystallogr. C62, o216 (2006).

[17] Z. Czapla, S. Dacko, A. Waskowska, J. Phys. Condens. Matt. 15, 3793 (2003).

[18] A. Dakhlaoui, L. S. Smiri, A. Driss, Acta Crystallogr. E60, o2241 (2004).

[19] J. Bernstein, R.E. Davis, L. Shimoni, N.-L. Chang, Angew. Chem. Int. Ed. Engl. 34, 1555 (1995).

[20] G. M. Sheldrick, SHELX-97, Programs for Crystal Structure Analysis, University of Gttingen, Germany (1997). 